\title{
Madres migrantes en la escuela mexicana. Su papel mediador
}

\section{Migrant mothers in the mexican elementary schools. The mediations}

Martha Josefina Franco García*

\section{RESUMEN}

Estudio de corte cualitativo cuyo propósito es analizar las mediaciones que realizan madres migrantes con sus hijos, nacidos en Estados Unidos, en su inserción a la escuela mexicana. Partimos del supuesto que el Estado no tiene en el centro del debate político la realidad trasnacional que impacta y moviliza a población infantil de Estados Unidos a México; por ello, reconocer el papel de las madres y sus demandas, permite identificar las necesidades de formación de los niños trasnacionales y el papel activo y propositivo de estas que bien debe reconocer y atender el Estado. Llevamos a cabo esta investigación en la comunidad de Nealtican, Puebla, en una primaria donde estudian veinte niños inmigrantes.

Palabras clave: madres, estudiantes inmigrantes, mediación, escuela

\section{ABSTRACT}

The main objective of this qualitative research is analyze the mediations between migrant mothers and their sons and daughters born in the United States of America (US) through their incorporation to mexican elementary schools. We assumed that the Mexican State has not recognized the transnational reality in the receant history that affects the children in their returning from the US to Mexico. This important point let us to identify the important activities the mother realize in the education of their sons and daughters when they arrive to mexican elementary schools. The research is based on interviews and was realized with twenty migrant children in a town named: Nealtican, in Puebla state in Mexico.

Key words: mothers, students, mediation, school

\section{Introducción}

La movilidad de población mexicana entre nuestro país y Estados Unidos es histórica (Durand y Massey, 2009) y ha permeando en espacios tan íntimos como la familia, haciendo de esta una compleja experiencia parental (Ariza y Oliveira 2001, Valdéz 2012), con evidentes repercusiones sociales y subjetivas.

En esta forma de vida, los niños han estado presentes, en especial en relación con sus madres que, tradicionalmente, han

\footnotetext{
•Universidad Pedagógica Nacional Unidad 211, Puebla; marthafrancog@hotmail.com
} 
cumplido un papel importante en la crianza y responsabilidad con sus hijos, lo mismo que en su escolarización. Esto no es reciente; en el Programa Bracero (1942-1964) cientos de mujeres y niños llegaron a Estados Unidos y, pasado el tiempo, muchos de ellos alcanzaron la nacionalidad (Durand 2005, 2007, y Bustamante 2007 citados en Valdéz, 2012).

Esta población realizó una vida familiar en la que la formación de sus hijos fue un acto de vida cotidiana. Y, aunque las cifras indican que la mayor parte de los migrantes eran población masculina en edad laboral (Durand y Massey 2009, Trigueros 2004), las mujeres y nińos constituyeron, de manera invisibilizada, parte de la comunidad mexicana en aquel país.

En la década de los noventa existe un detonador de la migración: la aprobación, en 1986, del Acta de Reforma y Control de Inmigración (Ley Simpson-Rodino) que "dio amnistía a las y los mexicanos que habían vivido en los Estados Unidos desde 1981. Esto dio pie a que muchas familias de inmigrantes con permiso legal para permanecer en Estados Unidos se reunificaran" (López, 1997; Durand y Massey, 2009; Trigueros, 2004; Cortina, 2010/2011: 121). Smith (2004: 91) tipifica este acontecimiento como la tercera fase de las migraciones de mexicanos hacia Estados Unidos, nombrándola como una explosión por el flujo masivo que la caracterizó. En esta fase hubo "un incremento en el número de mujeres y niños que entraron a formar parte del flujo migratorio" (López, 1997).

También propició la posibilidad de procreación, que fue grande, ya que los datos demográficos señalan que "las mujeres mexicanas poseen las tasas más altas de nacimientos del grupo de madres nacidas en el extranjero" (Cortina, 2010/2011: 117; cfr. Pew Center, 2010). Con ello, la población de niños de familias migrantes creció en Estados Unidos cerca de 50\% en los años noventa (Hernández y Charney, 1998 en Yu, Huang, et al., 2003. cfr. Smith, 2004).

Luego del nacimiento de la segunda generación en el país vecino y ante la migración infantil, son cada vez más visibles los niños de origen mexicano, sobre todo por la necesidad y la demanda que realizan sus padres de servicios públicos, los cuales están estipulados en la Convención sobre los derechos del niño (UNICEF,1989). 
Como respuesta, el Estado de aquel país ha impulsado dos tipos de acciones, aparentemente contrapuestas: por un lado, políticas sociales de orden compensatorio que, en cuanto a educación, implantan programas educativos bilingües, tutorías y otros apoyos adicionales para compensar las desventajas sociales, culturales y lingüísticas de estos estudiantes en el sistema escolar (a nivel federal, estatal y distrital), pero siempre los confina a escuelas pobres y conflictivas (cfr. Mc Carthy, 1994; Mc Laren, 1999; Cortina, 2010-2011).

Por otro lado, endurece sus acciones ante la migración indocumentada, ya que entre 2010 y 2014 realiza 1.6 millones de repatriaciones de connacionales desde Estados Unidos (Jacobo, 2016: 1), mientras que, en toda la administración de Barack Obama, fueron 2.8 millones de deportados, y se espera que en la administración de Trump esta cifra sea mayor.

En la ampliación de los territorios de circulación, concomitantemente, se observa la implantación de linderos y clausuras cada vez más rígidos para las segmentaciones demográficas y geopolíticas en los que estos flujos son posibles, y una restricción tajante a la capacidad de acceso a los beneficios (Mier, 2003: 5-6).

En este contexto de control estratégico estadounidense que, en el plano de mayor condescendencia, asume una tolerancia represiva, actualmente aprieta con un proceder contundente: procesos de deportación y repatriación infantil, ${ }^{1}$ sin tomar en cuenta género, edad, problemática social, condiciones familiares, etc., cuestión que impacta la dinámica familiar e incluso el tejido social al violentar, de manera directa o tangencial, los derechos humanos de los infantes.

Esto produce una realidad compleja pues, si de antemano, la relación entre migración e infancias teje en las subjetividades infantiles experiencias enfocadas a, en palabras de Mier, "sobrevivir

${ }^{1}$ UNICEF (s/f) refiere que "cada año, alrededor de 40 mil niños y niñas que migran son repatriados desde Estados Unidos a México, de estos, 18000 viajan solos". Es importante señalar que se ha considerado que estas deportaciones junto con la de niños centroamericanos, por su gran número y la preocupante violación a los derechos humanos de que son víctimas, ha originado una crisis humanitaria en la región (Periódico La jornada, 2 de julio de 2014). 
al allanamiento incesante de las identidades, a la devastación de los entornos, al recrudecimiento del silencio y la invisibilidad" (2003: 21), al sufrimiento generado por la exclusión, la segregación y la incertidumbre que el cuidado familiar y comunitario intenta contrarrestar en la diáspora.

Posteriormente, cuando la familia retorna o realiza una migración pendular, los niños no toman parte en esas decisiones (Valdéz, 2012); sin embargo, "constituyen el eje central de la migración familiar y, con frecuencia, son un argumento crucial por el cual la familia se traslada a un lugar" (Levitt y Glick, 2006: 206). Con ello advertimos como paradoja que, si bien los niños son los más vulnerados en la migración y asumen las consecuencias de las determinaciones que toman los adultos, son también a quienes la familia tiende a proteger de manera privilegiada y en la medida de sus posibilidades.

Producto de la constitución familiar en un ámbito de desplazamiento, "en muchos casos la socialización y la reproducción social acaecen transnacionalmente en respuesta a cuando menos dos contextos sociales y culturales" (Levitt y Glick, 2006: 207), cuestión que hace compleja la inserción de estos niños al campo social y a sus instituciones, donde no se reconocen ni atienden sus necesidades básicas de vida trasnacional (Zúñiga, 2013), Franco, 2014; Jacobo, 2016).

Así, ante los procesos de retorno que viven actualmente familias y niños transmigrantes, partimos del supuesto que el Estado mexicano no tiene en el centro del debate político esta realidad trasnacional que impacta y moviliza a población mexicana, de manera libre o forzada, de Estados Unidos a México, sino apenas algunas acciones desdibujadas de la Secretaría de Gobernación, la Secretaría de Educación Pública y del Sistema de Salud reconociendo, en cambio, que son las familias y, en particular, las madres, quienes hacen frente a esta situación, desempeñando un papel fundamental de mediación entre la realidad social trasnacional y sus hijos. De manera específica, nos centramos en la mediación de las madres en relación con la escolarización de sus hijos.

Reconociendo la importancia de la familia y en especial de estas últimas en asumir los retos que implican la movilidad y la formación trasnacional de sus hijos, nos planteamos el propósito 
analizar las mediaciones que realizan madres migrantes con sus hijos, nacidos en Estados Unidos, en su inserción a la escuela mexicana, ante la falta de políticas públicas pertinentes para los niños deportados.

Para ello, realizamos un estudio de corte cualitativo en una escuela primaria de la comunidad de San Buenaventura Nealtican, Puebla, donde asisten 20 niños migrantes. El trabajo atento, cara a cara, nos permitió el reconocimiento comprensivo de las prácticas discursivas de los actores sociales. Las observaciones realizadas y las entrevistas recogidas en el propio mundo de la vida ${ }^{2}$ generaron datos descriptivos que nos permitieron conocer la situación en que los estudiantes inmigrantes se inscriben a la escuela a través de la mediación que realizan las madres, advirtiendo el sentido ${ }^{3}$ implícito en ello.

Realizamos el trabajo de campo en la escuela primaria Niños Héroes de Chapultepec, escuela de educación indígena ${ }^{4}$ que desde hace dos décadas recibe niños inmigrantes. Allí identificamos a los niños que tenían experiencias escolares en Estados Unidos y realizamos un cuestionario a sus madres (veinte en total), entrevistas a profundidad a seis de ellos y a sus madres, a seis profesores (uno por grado), al director de la escuela, además de cuatro observaciones de clase y registro de la cotidianidad escolar. Los resultados de nuestro acercamiento a esta realidad recuperan la información de todos nuestros entrevistados; sin embargo, los datos empíricos (testimonios textuales) que presentamos en el cuerpo del trabajo son únicamente de los niños migrantes y de sus madres.

A continuación, describimos el contexto al que llegan las familias transmigrantes $y$, posteriormente, el sustento teórico de

\footnotetext{
2"El mundo de la vida, entendido en su totalidad, como mundo natural y social es el escenario y lo que pone límites a mi acción y a nuestra acción recíproca” (Schutz y Luckmann, 2009: 27).

3 "El sentido es el resultado de la explicitación de vivencias pasadas que son captadas reflexivamente desde un ahora actual y desde un esquema de referencia actualmente válido" (Schutz y Luckmann, 2009: 35,36).

${ }^{4}$ En esta escuela, los niños ya no hablan la lengua originaria y, aunque la mayoría de los maestros y el director son bilingües (en náhuatl y español), solamente realizan actividades de revitalización del náhuatl en la asignatura de lengua indígena (una hora a la semana), carteles de señalización en dicho idioma, cantan el himno nacional en forma bilingüe y realizan saludos en esa lengua. Pero el currículum con el que trabajan es el nacional y la lengua en que se imparte es el español.
} 
la mediación y la acción mediadora que realizan las madres para posibilitar que sus hijos se integren al espacio escolar.

\section{Nealtican, un poblado rural-urbano al que llegan familias migrantes}

En las faldas del volcán Popocatépetl, en el estado de Puebla, se ubica San Buenaventura Nealtican, un poblado rural-urbano con raíces nahuas donde prevalece el vínculo con la Madre tierra a través de la actividad agrícola y se mantienen diversas costumbres familiares y comunitarias como la gastronomía, que privilegia el empleo de maíz, frijol y calabaza en la elaboración de los alimentos, el uso del náhuatl entre los abuelos, las celebraciones religiosas, como la fiesta patronal, el 14 de julio, el pedimento de la novia y posterior boda, donde se baila el xochipizaua ${ }^{5}$ y la festividad de muertos. ${ }^{6}$

En este espacio, donde se realizan prácticas ancestrales, se observan también actividades modernas, globalizadas, como la vestimenta, el uso de celulares; el empleo de los mass media, la ocupación de maquinarias para el trabajo agrícola, en la empresa tortillera y blockera; el uso de transportes, la vinculación comercial con el exterior, la demanda de múltiples servicios; el consumo de mercancía globalizada, la constante ampliación de infraestructura y, por supuesto, una dinámica migratoria que mueve a $7 \%$ de la población en un circuito trasnacional que se arma entre este lugar y Nueva York, a partir de redes sociales tendidas entre ambos sitios (que repercute de manera social, económica y subjetiva en el resto de la población), el uso de la telefonía entre naciones, el Internet y la cotización de propiedades en dólares.

\footnotetext{
${ }^{5}$ El pedimento de la novia es un evento protocolario de gran importancia, donde el novio y su familia se hacen acompañar de un poblador con prestigio en la comunidad, quien solicita la mano de la novia para el joven casadero. El pedimento tiene que ver con una mediación entre familias a partir de un tercero, que es reconocido, y tiene la función de conferir validez social al acto. En la boda se baila el xochipizaua, donde intervienen, en primer término, los compadres y familiares y, posteriormente, los invitados, en un acto de comunión de los participantes. Este baile también se realiza en actividades religiosas como el 12 de diciembre, día de la virgen de Guadalupe.

${ }^{6}$ En esta festividad, las casas donde hubo un difunto en ese año reciben a toda la comunidad, que se presenta con un cirio y alimentos para la ofrenda, que se vuelve comunitaria. En esa casa, los deudos ofrecen alimentos a todos sus visitantes.
} 
La población total en Nealtican, según el censo del 2010, es de 12011 habitantes; de ellos, la población de cinco años y más que asiste a la escuela es de 3596 (INEGI, 2011). Sus instituciones educativas son: un preescolar general y dos de educación indígena; tres primarias generales y una indígena; una secundaria general, una técnica y un bachillerato.

Desde este espacio sociocultural, se ha desplazado hacia Estados Unidos, de manera gradual (desde finales de los ochenta), población económicamente activa, en busca de mejores oportunidades de vida o con la intención de construir un proyecto personal o familiar diferente. En este contingente encontramos a mujeres jóvenes, quienes construyen una biografía laboral y familiar trasnacional.

En la actualidad, se advierte en el poblado que algunas familias, por diversos motivos, han retornado con sus hijos, en un fenómeno que podemos considerar como migración de retorno de los padres, y cuyos hijos, por lo común, han nacido en Estados Unidos, tienen la nacionalidad estadounidense y llegan, por decisión "familiar", a Nealtican. Estos son recibidos de manera hospitalaria e incorporados a dinámicas parentales de tíos, primos y abuelos. No obstante, también se inscriben a la escuela, incluso si desconocen la operatividad de la institución y las significaciones internalizadas por sus actores sociales.

En Nealtican, la escolarización promedio de la población de quince ańos en adelante es de 6.4 grados, menor que el promedio de la entidad poblana, que es de 8.0 grados, y la nacional, que es de 8.6 (INEGI, 2011). Esto nos muestra que el poblado ha estado en desventaja en cuanto al acceso y permanencia de sus habitantes en el Sistema Educativo Mexicano, lo que impacta en la escolarización de los niños tanto en Estados Unidos como en México, ya que la baja escolarización de sus padres y abuelos les dota de un capital cultural escolar -CCE- (Bourdieu y Passeron, 2003) ${ }^{7}$ que los pone en desventaja en su tránsito por los dos sistemas educativos, ya que existe una

\footnotetext{
${ }^{7}$ El CEC está conformado por la escolaridad de los padres, sus expectativas escolares (respecto a la educación de sus hijos), la frecuencia con que se asiste al cine, la posesión de libros y el acceso de Internet en casa" (Backhoff et al., 2007: 26).
} 


\section{relación directa entre el CCE y el aprendizaje de los contenidos escolares. ${ }^{8}$}

En el caso de las madres migrantes de esta investigación, el nivel de escolaridad promedio de diecinueve de ellas ${ }^{9}$ es de 7.6 años (mayor que la media del municipio, sin embargo, se mantienen por debajo de la media estatal y nacional y con rezago educativo). Sus estudios son de secundaria no concluida. Con la escolaridad cursada en México, ellas se iniciaron en la vida laboral en Estados Unidos y formaron una familia.

A la baja escolaridad de las madres se suman otros factores que afectaron el bienestar social y educativo de sus niños en Estados Unidos: la condición de su familia como inmigrantes ilegales, las extenuantes jornadas laborales de los padres, el nivel socioeconómico, el desconocimiento del idioma inglés, el racismo estadounidense, todos factores que inciden de manera directa en el aprendizaje.

Me iba a trabajar y dejaba todo preparado para que mis hijos se fueran a la escuela, una vecina pasaba por ellos y los llevaba al colegio, la escuela allá es diferente, las materias, las clases. Mis hijos estaban en los grupos en español y ya iban a unas clases también en inglés con el grupo general. Pocas veces fui; sí tenía que ir, me llamaban, pero no siempre podía por el trabajo, me mandaban por escrito algunas informaciones. Asistí a las reuniones que hacían casi por la noche, me explicaban que tenía que ayudar a mis hijos. Cuando regresaba del trabajo, les preguntaba si ya habían hecho su tarea $\left(\mathrm{M}^{\circ}\right)$.

\footnotetext{
${ }^{8}$ Backhoff (2007) refiere que el estado de Puebla se encuentra por debajo de la media nacional en CCE de sus estudiantes, advirtiendo una relación directa del CCE con los resultados académicos y socioeconómicos. En Nealtican existe $86.1 \%$ de población en situación de pobreza y, de ella, $22.1 \%$ en pobreza extrema (CONEVAL s/f). Estos datos tienen relación con los bajos niveles de escolarización de la población mayor de quince años, lo que repercute, como lo hemos revisado, de manera directa en el CCE de las nuevas generaciones.

${ }^{9}$ La otra madre no es oriunda de Nealtican; ella nació en Durango y estudió en Estados Unidos desde la educación elemental hasta el Community College. Formó una familia y trabajó en Estados Unidos. Su inscripción temprana a la escuela de aquel país y el nivel escolar logrado le permitieron integrarse, junto con sus hijos, a la comunidad y a la escuela estadounidense de manera exitosa; no obstante, ella y su esposo deciden reincorporarse a la comunidad de origen de este. El nivel de escolarización de esta madre y su absorción a la cultura estadounidense es excepcional entre los casos de la mayoría de las madres migrantes de la región de los Valles Centrales de Puebla, lugar donde se ubica este estudio.
} 
Como vemos en este testimonio, la participación de las madres en la escuela estadounidense y el apoyo que brindaron a sus hijos fue muy limitado, lo que repercutió en los procesos escolares de estos últimos. Al respecto encontramos una gran producción de investigaciones (Cortina, 2004; López, 1997; Smith, 2004; Suárez y Baolian, 2004 y Tinley, 2006) que reconocen, entre las causas que afectan los procesos de aprendizaje de los niños inmigrantes en las escuelas de Estados Unidos, que los padres no pueden ayudarlos en casa, además de los obstáculos socioeconómicos familiares.

Los padres, al desconocer el funcionamiento del sistema educativo estadounidense, agregan una cuota de tensión al proceso de enseñanzaaprendizaje del niño, ya de por sí difícil debido a las condiciones en que se da. En parte debido a ese desconocimiento, al no dominio del inglés y las agotadoras jornadas de trabajo a las que normalmente se somete un migrante, por tales razones, los padres tienen una escasa participación en las decisiones escolares, en el seguimiento del rendimiento escolar del niño y en la organización de la escuela y los programas en que se inscribe su hijo (López, 1997: 4).

Suárez y Baolian (2004) señalan que los fondos de conocimiento de los niños inmigrantes y sus familias dificultan su éxito escolar, ya que estos conocimientos se relacionan con la experiencia de vida de las clases medias estadounidenses (cfr. Bourdieu y Passeron, 2003). El fondo de conocimientos tiene relación con el CCE planteado por Backhoff (2007) y ambos no son suficientes para que los niños de origen mexicano tengan éxito en las escuelas del vecino país.

Por ello, los estudios sobre el aprendizaje de los niños inmigrantes en Estados Unidos coinciden en la necesidad de incorporar a las madres y a los padres en los procesos educativos de sus hijos e incluirlos como sujetos de aprendizaje (Cortina, 2010/2011, Smith, 2004). Y es que "se advierten los impactos positivos respecto a la educación de las madres y padres en el desarrollo de sus hijos e hijas, no solo en relación con los indicadores escolares, sino también en términos de salud, nutrición, cuidado y bienestar general" (Torres, 2006: 13). 
En el caso de las madres que nos ocupan (excepto una), de manera precaria y en condiciones difíciles, tuvieron contacto y experiencias $^{10}$ con las escuelas estadounidenses; no obstante, aprendieron de manera elemental a identificar la forma de ingreso a ellas, los requerimientos que les establecen, la forma en que se organizan, los recursos con los que cuentan (materiales y humanos), los apoyos especiales que brindan, las formas en que deben participar, los procesos de aprendizaje de sus hijos y la forma de enseñanza bilingüe, todo esto a partir de los años en que sus hijos estuvieron escolarizados. Esta experiencia con la escuela de sus hijos en Estados Unidos les permite reconocerla como un espacio fundamental para la apropiación de la cultura en esa sociedad (cfr. Bourdieu y Passeron, 2003).

De retorno a México, las madres con experiencias de escolarización en este país y con conocimientos sobre el funcionamiento y organización de las instituciones escolares estadounidenses, se acercan a las escuelas mexicanas con el propósito de que sus hijos ingresen a ellas. En este acercamiento, ellas adquieren un papel más activo que el que tuvieron en Estados Unidos, debido a que su rutina es más tranquila. En este escenario, se constituyen como mediadoras entre sus hijos y la institución educativa.

\section{Mediación en un contexto transnacionalizado}

Empleamos como noción ordenadora la mediación, que en latín tiene varias acepciones: intercessio, onis (intercesión, interceder y oposición, ponerse frente a); interpösitio onis (interposición, interponerse entre uno y otro) e interventus, us (llegada, acontecimiento imprevisto, inesperado) (Blanquez, 1978: 624). Al hacer una lectura de estos términos encontramos que en todos aparece el prefijo inter, que representa entre; es decir, que en el proceso de mediación existe la posición de un tercero relacional con una función movilizadora que, en tanto cuanto intercede y relaciona, se pone en frente con el propósito de intervenir y como acontecimiento que trastoca lo constituido para dar paso a algo más.

\footnotetext{
${ }^{10}$ Ferry, citado en Dewey, señaló que "La experiencia es una investigación existencial, a la vez prueba y acción" (1994: 101); Larrosa puntualiza que la experiencia tiene que ver "con lo que acontece. Es el modo de habitar el mundo de un ser que existe" (2003: 5).
} 
Desde esta concepción, reconocemos el papel de las madres como intermediarias entre la institución escolar y sus hijos, como alguien que está entre la realidad, en este caso escolar, y el sujeto de la experiencia, en este caso el estudiante inmigrante. Pensar de esta manera la mediación nos permite plantear que su importancia no es determinarla únicamente como un medio o instrumento, sino para identificar más allá de esto, que no podemos suponer algo puro y directo entre las cosas y el viviente; de esta manera, su posición es configurativa (Martínez, 2014). Esta última consideración muestra lo sustantivo de la mediación en la trama social y educativa.

De esta forma, la mediación se inscribe en el campo de lo social, porque posibilita la acción entre el sujeto y las cosas, los otros sujetos, las instituciones e incluso las culturas. En el campo educativo, la mediación está presente en la formación ${ }^{11}$ como una posición configurativa.

En el paradigma sociocultural, Hernández (1998) refiere que, en la Zona de Desarrollo Próximo ${ }^{12}$ planteada por Vigotsky (2013), cobra importancia el estudio de la mediación en contextos sociales, pues a través de esta, el sujeto puede lograr el nivel de desarrollo potencial, bajo la intervención educativa del otro. En este sentido, diferentes actores sociales intervienen en la formación del sujeto y es la madre, entre otros, la primera mediadora entre el sujeto y las pautas culturales del grupo social. ${ }^{13}$ Posterior-

\footnotetext{
${ }^{11}$ Entendemos la formación "como un proceso cuyo movimiento se asemeja a una espiral. El sujeto recibe de la sociedad y la cultura los elementos que le permiten desarrollarse y configurar su personalidad. A su vez, el sujeto actúa consciente, crítica y creativamente sobre su entorno social y cultural para transformarlo y transformarse. Es, en suma, el movimiento del para sí" (Yurén, 2000: 9). Diversos discursos interpelan al sujeto, el cual, en un acto reflexivo, realiza un proceso de significación y acción de la realidad. La formación es un proceso para situarse y transformar la realidad, un ejercicio pleno, de búsqueda, que tiende a constituir al sujeto, a partir de saberes que le permiten leer y apropiarse del mundomundos de la vida. Así, sus actos educativos, se arman desde la recuperación de legado que da sentido y cohesión social, pero también desde actos transformadores.

${ }^{12}$ La Zona de Desarrollo Próximo es "la distancia entre el nivel real de desarrollo determinada por la capacidad de resolver independientemente un problema, y el nivel de desarrollo potencial, determinado a través de la resolución de un problema bajo la guía de un adulto o en colaboración con otro compañero más capaz" (Vigotsky, 2013: 133).

${ }^{13} \mathrm{La}$ noción de pauta cultural de la vida grupal tiene que ver con "todas las valoraciones, instituciones y sistemas de orientación y guías peculiares (tales como usos y costumbres, leyes, hábitos, etiqueta y modas) que... caracterizan -cuando no constituyen- todo grupo social en un momento determinado de su historia" (Schutz, 2012: 28). Es una construcción social de sentido que se trasmite como legado permitiendo no solo situarse culturalmente
} 
mente, el abanico de interventores se amplía de manera formal e informal, teniendo posteriormente un papel importante los parientes, amigos, el profesor, etcétera.

Cuando Vigotsky (2013) hace referencia a las funciones psicológicas superiores, cobra importancia la mediación sociocultural porque son específicas del hombre en cuanto sujeto inscrito en un contexto cultural. En este ámbito, es precisamente la mediación la que posibilita que se originen dichas funciones. ${ }^{14}$

Los planeamientos vigotskianos se sustentan tanto en los sujetos mediadores como en la mediación de los instrumentos culturales para el aprendizaje. Y por supuesto, el lenguaje es el instrumento de mayor importancia que en el caso que nos ocupa: se enseńa en casa para transmitir la pauta cultural de la vida grupal. Esto determina de manera importante la constitución endógena en la diáspora, porque la lengua, en este caso el español, además de estar estructurada por símbolos lingüísticos, conlleva términos que tienen diversas connotaciones según el contexto o situación referida y existen giros lingüísticos, jergas, dialectos, etc., todo esto, producto de la dinámica social que permite que converjan cultura, pensamiento y lenguaje, ${ }^{15}$ este último como un instrumento mediador del grupo social.

en el contexto, también reconocerse desde el nosotros a través de las prácticas sociales que de forma cotidiana se ejercitan de manera legítima en todos los órdenes de la vida social. En este caso, advertimos que en los espacios trasnacionales, los sujetos experimentan vivencias en pautas culturales distintas que los sitúan en procesos de comprensión y actos estratégicos en la vida cotidiana. Schutz (2012) refiere que "el forastero comienza a interpretar su nuevo ambiente social en términos de su pensar habitual. Sin embargo, encuentra dentro del esquema de referencia que trae de su grupo de origen una idea ya elaborada de la pauta supuestamente válida dentro del grupo al que se incorpora, idea que, inevitablemente, no tardará en resultar inadecuada... Por lo que la pauta cultural del grupo abordado va a dejar de ser un objeto de su pensamiento, para pasar a ser un sector del mundo que debe ser dominado mediante acciones. En consecuencia, la posición que dicha pauta dentro del sistema de relevancias del forastero cambia decididamente y esto significa que su interpretación requiere de otro tipo de conocimiento" (Schutz y Luckmann, 2009: 33-34).

${ }_{14}$ "Con el proceso de mediación cultural, gracias a las actividades mediatizadas por instrumentos (especialmente el lenguaje y el trabajo) en prácticas colectivas, se originan las funciones psicológicas superiores... Lo verdaderamente determinante es la condición sociocultural en que se desarrollan, en tanto que el sujeto, miembro de la cultura usa distintos mediadores en situaciones de aprendizaje compartido" (Hernández, 1998: 223).

${ }^{15} \mathrm{La}$ lengua que se aprende con el grupo social, encierra visiones del mundo, referentes comunes, metáforas propias que son inteligibles para el grupo. Toda palabra y toda oración está rodeada -recurriendo a un término sugerido por William James- por "orlas" que las conectan, por una parte, con elementos pasados y futuros del universo del discurso al que pertenecen y, por otra, las circundan con un halo de valores emocionales e implicaciones irracionales que son, en sí mismos, inefables (Schutz, 2012: 37). 
Advertimos entonces que las madres realizan dos papeles importantes en relación con la mediación: primero, como intervención, que permite que los nińos y jóvenes se articulen a la realidad socialmente construida a partir de las experiencias vividas; es decir, son mediadoras entre la realidad social escolar y sus hijos, y después, acercan a sus hijos a la mediación de instrumentos culturales como el lenguaje.

Para mostrar los actos de mediación que realizan las madres respecto a la escolarización de sus hijos, vamos a trabajar cuatro aspectos que identificamos como nodales en los relatos de los actores educativos, principalmente de las madres y de los estudiantes: Uno, los procesos de inserción de los niños a la escuela de Nealtican; dos, la lengua como instrumento de mediación; tres, las formas de aprender y, cuatro, las demandas y determinaciones que hacen las madres en relación con la escuela mexicana.

\section{Mediación en el proceso de inserción de los niños transmigrantes}

Con el reconocimiento y apropiación tanto de la pauta cultural del grupo endógeno y el proceso de inserción a la vida social en Estados Unidos, las familias retornan a Nealtican reincorporándose a la comunidad, que para los padres constituye "lo propio" $y$, para los hijos, un reconocimiento de ese nuevo espacio que tendrán que comprender y apropiase.

En la vida cotidiana en Nealtican, se observa un cambio en la forma de vida familiar. Los padres van a organizar sus actividades de manera diferente de como lo hacían en Estados Unidos. En principio, ya no están fuera de casa todo el tiempo ${ }^{16}$ y no se muestran agobiados por la actividad laboral. La madre, generalmente, está más tiempo con los hijos, lo que modifica el ritmo y la relación de la vida familiar. En este aspecto, la madre se acerca a la escuela de manera activa con la intención de apoyar a sus hijos. En principio realizan los trámites de inscripción.

A mí me mandaron a esta escuela porque era bilingüe, después entendimos que lo que enseńaban era náhuatl y español y yo lo que buscaba era

\footnotetext{
${ }^{16}$ Aunque tres padres sí están fuera de Nealtican y llegan a casa los fines de semana.
} 
que mi hija siguiera con el inglés. De esas escuelas no hay aquí, solo que pagues $\left(\mathrm{MF}^{17}\right)$.

La búsqueda de una escuela acorde con las necesidades de formación de estos niños es difícil. Prácticamente no hay, en la comunidad, escuelas realmente bilingües (en español e inglés). Además, en ocasiones, las escuelas públicas no aceptan a estos niños porque a los maestros se les complica trabajar con ellos: "en la escuela del centro no me la recibieron, dicen que ellos tienen el cupo lleno y que no pueden atender a los alumnos que vienen hablando inglés" (MF4).

Sin embargo, también los parientes apartan, con anticipación, un lugar para estos niños en las escuelas. La preocupación por asegurar un lugar no garantiza que la institución sea apropiada para la formación de estos estudiantes trasnacionales; sin embargo, los familiares o las propias madres inscriben a estos niños formalizando su escolarización, a la espera de que la escuela cumpla su cometido. Desde ese momento, estos estudiantes transitan por la escuela mexicana con la mediación de sus madres que sí conocen la gramática escolar ${ }^{18}$ (Tyack y Tobin, 1993) de la institución.

Las prácticas disciplinarias instauradas por los profesores exigen a los estudiantes ceñirse a códigos de conducta inscritos en la obediencia, sin reconocer las actitudes sociales que aprendieron en la escuela estadounidense como decir lo que piensan, participar de manera desenvuelta y reconocer que tienen derechos. Esto irremediablemente confronta a los niños: "Sí, es distinto, debemos obedecer en todo" (E $\left.5^{\circ}\right)$, "No sabía que debemos pedir permiso, pero si no, el maestro se enoja, ya estoy aprendiendo" $\left(\mathrm{E} 4^{\circ}\right)$, “aquí regañan" $\left(\mathrm{E} 1^{\circ}\right)$.

En el tránsito de un sistema escolar a otro, las y los estudiantes inmigrantes tienen como referentes para mirar y aprehender lo que acontece en la nueva institución y el papel que ellos juegan

\footnotetext{
${ }^{17}$ Cuando se trate de madre de familia, vamos a poner MF y un número consecutivo. Cuando es un estudiante E y el grado en que está.

${ }^{18} \mathrm{La}$ gramática escolar tiene que ver con "las formas organizativas que gobiernan la institución, particulares modos de organización y formas estandarizadas de concebir el tiempo y el espacio escolar, transmisión de saberes, la asignación de calificaciones, la división de los alumnos en aulas, la tarea de los docentes, sedimentada a lo largo de décadas; esta gramática habría sido interpretada por alumnos y profesores como los rasgos constitutivos de una escuela verdadera o auténtica" (Tyack y Tobin, 1993: 454).
} 
en ella, sus experiencias escolarizadas previas. De esta manera, se van abriendo paso intentando poner a prueba la experiencia anterior, sin embargo, con esto, suelen confrontar a la escuela que los recibe. Por su parte, las madres advierten estas diferencias:

Allá [en Estados Unidos] se trabaja la disciplina pero como una responsabilidad común, los maestros enseñan que deben respetar y llegar a acuerdos para estar mejor, también los niños adquieren en la escuela una buena actitud, que no tengan vergüenza de preguntar, allá les dan su tiempo por si no entienden algo y eso les ayuda y se sienten seguros, pero acá es diferente y a los nińos les cuesta entenderlo (MF1).

Las prácticas descritas por la madre de familia (quien tiene la experiencia de haber sido estudiante y madre de familia en los Estados Unidos), no se relacionan con la forma en que se instaura la disciplina en las aulas a las que llegan estas y estos niños. La escuela mexicana ejerce sobre ellos otro tipo de normas que regularán en adelante, su forma de comportarse.

Este tipo de normas impuestas por la escuela están inscritas, como refiere Foucautl (2005), en la microfísica del poder; es decir, en actos rutinarios que, más que castigos ejemplares, se inscriben en acciones permanentes que van moldeando de manera sutil la conducta de las y los estudiantes. Y es que la escuela mexicana mantiene, como parte de las prácticas inscritas en el quehacer escolar, la disciplina autoritaria como un fin educativo, obligando a los estudiantes a realizar actividades "en silencio", a levantar la mano para que el profesor permita que hablen; a aceptar la exigencia de que pidan permiso para ir al baño y empleen frases de obediencia para dirigirse a la autoridad educativa como: "mande usted", "me permite pasar", "con su permiso", etcétera.

Acciones y discursos normalizados en el aula mexicana que los alumnos inmigrantes desconocían y no comparten, pero que deben acatar. En este caso, identificamos que la mediación de las madres se advierte en los dos sentidos descritos en la noción de mediación. Uno de oposición. La madre 1 refiere de manera crítica esas formas de actuar: "esas normas no permiten que los niños estén tranquilos y contentos en la escuela. Yo se lo he comentado ya al director para que sepa que vienen con otras formas 
de actuar y no por ello están faltando al respeto" (M1). En este caso la madre media "entre" la autoridad y la forma en que su hija ha aprendido a comportarse en la escuela, en una postura de confrontar las reglas establecidas en la institución. En este caso intenta establecer otro orden para que sea respetada o por lo menos tolerada la forma en que su hija se desempeña en la institución.

El otro sentido es para intervenir intercediendo con sus hijos, explicándoles que deben ser obedientes en la escuela e incluso concuerdan con la disciplina autoritaria, ya que advierten que, en Estados Unidos, la escuela no permite que los padres repriman a sus hijos y estos no los obedecen.

En esta mediación, no en todos los casos los profesores están dispuestos a negociar o consensar con los alumnos y sus madres: simplemente vigilan que se cumplan las normas que ellos mismos imponen. En respuesta, las madres van a estar cercanas al profesor para conocer sus demandas, apoyar las decisiones que no incidan en la sensibilidad de sus hijos, pero también para oponerse cuando identifican que sobrepasan las relaciones de respeto entre maestro-alumno. La presencia activa de las madres en la escuela crea un vínculo que permite, o por lo menos intenta, que los profesores se sensibilicen al trabajar con estos estudiantes.

\section{La lengua, un instrumento de mediación cultural y enseñanza escolar}

La lengua es un instrumento importante en la mediación sociocultural debido a que transmite la forma de ver el mundo, pensarlo y enunciarlo. En este aspecto, las madres en Estados Unidos trasmitieron su lengua (el español), debido a que, en general, los padres suelen ser monolingües en español o además del español saben inglés pero de manera limitada. Esto permitió que, en la diáspora, transmitieran a sus hijos la pauta cultural del grupo social a través de su propia lengua. Por ello, cuando estos niños llegan a la escuela de Nealtican saben español.

En mi casa me hablaban en español y unas cosas también en inglés, pero mi mamá no dejó de hablarme en español, me decía que también tenía que saber escribir y me enseñaba $\left(E 4^{\circ}\right)$. 
Esto muestra el interés de la familia por mantener el español como vínculo de comunicación, la lengua se usa con fines coloquiales, no académicos; sin embargo, algunas madres también enseñan a sus hijos a escribirlo y esto permite que ellos se incorporen y trabajen en la escuela con mayor facilidad, ya que, como refiere Czarny (2007), la escuela mexicana inscribe fuertemente sus procesos de enseñanza aprendizaje, en la lectura y la escritura del español.

Las narraciones de las y los alumnos inmigrantes sobre las dificultades que tuvieron en lectoescritura, nos muestran los apoyos elementales que les brindan los docentes en este aspecto:

Cuando vine, sabía más inglés y me confundía en las palabras. Aunque sabía español porque mi mamá me había enseñado a escribirlo y hablarlo pero yo sabía más inglés. A veces no podía apurarme, no me fijaba y la maestra ya había borrado. Otras veces lo escribía en inglés y lo llevaba a calificar así. La maestra me decía que así estaba en inglés y me fijaba y lo corregía al español" (E $\left.4^{\circ}\right)$.

Los procesos de adquisición de la lengua son prolongados y conllevan cuatro habilidades (hablar, escuchar, leer y escribir); para ello, las madres intervienen, unas más que otras, pero siempre lo hacen en procesos largos. Algunas enseñaron a hablar en español a sus hijos, habilitándolos también a escuchar en los propios procesos comunicativos.

Otras, además de enseñarlos a hablar y a escuchar, los acercaron a la lectura y escritura. Algunas familias ejercitaron ex profeso las cuatro habilidades comunicativas, en el caso de $\mathrm{E}^{\circ}$, además de aprender a escribir, le compraban revistas y cuentos en español. ${ }^{19}$

Reconocemos, entonces, que la apropiación del español se dio en un proceso de larga duración: inicia en Estados Unidos y se mantiene en México. Las madres median en este proceso desde los primeros años de vida de sus hijos y a partir de sus propias iniciativas e intereses. Y ya en la escuela mexicana se preocupan porque lo antes posible logren leer, escribir y tomar dictados.

\footnotetext{
${ }^{19}$ Es de mencionar que las escuelas que atienden el bilingüismo en Estados Unidos también tienen libros y revistas en español, lo que permitió que los niños leyeran en ese idioma.
} 
Por otro lado, está el inglés. Los niños hablan inglés, habilidad comunicativa importante en su formación y en su vida trasnacional, sin embargo, la escuela mexicana no brinda una enseñanza bilingüe (inglés y español), por ello, las madres tratan de que sus hijos hablen inglés en casa, lean libros y vean películas en ese idioma.

A pesar del interés de las madres y de los estudiantes por ejercitar los dos idiomas, estos dejan de hablar inglés como lengua de aprendizaje académico. No obstante, en un intento de que lo sigan haciendo, tres niños dejaron la escuela pública para irse a una escuela privada que ofrece la enseñanza del inglés.

Advertimos el interés de los padres por una formación pertinente para sus hijos. En este caso, las madres median entre la oferta educativa curricular y la formación de sus hijos con el interés de lograr el bilingüismo. Para ello, lamentablemente, la escuela pública no es opción y los envían a escuelas privadas.

\section{Formas de aprender en contextos trasnacionales}

Los estudiantes migrantes realizan un cruce de fronteras entre las instituciones educativas de Estados Unidos y México, ya que son dos proyectos educativos distintos que mantienen, cada uno por su parte, aspectos como lengua, cultura, identidad nacional, etc., que se transmiten de manera relevante, cuestión que al ser diferente en uno y otro países, obliga a estos estudiantes a aprender dos maneras de ser y estar en las escuelas.

Además de eso, los estilos de trabajo de los profesores y la organización de los planteles suelen ser también diferentes. En relación con el estilo de trabajo, un estudiante migrante refiere que en México "el profesor sí enseńa bien, pero a veces me distraigo y no entiendo. Si no entendemos, el maestro nos explica y nos regańa si nos distraemos" $\left(\mathrm{E} 5^{\circ}\right)$.

El proceso pedagógico de enseñanza-aprendizaje es diferente en Estados Unidos y México. Cambian asignaturas, contenidos, la lengua de enseñanza, horarios, procesos didácticos, las dinámicas áulicas, materiales, apoyos docentes (asistentes) y la interacción.

Incluso, podemos advertir que, a diferencia de México, donde se trabaja un currículo nacional, en Estados Unidos existe 
un rango diverso de decisiones políticas y con ello experiencias educativas diversas dependiendo del Estado, el distrito y la escuela (Martínez, 2011). Por ello, existen múltiples propuestas de atención a los estudiantes; no obstante, en escuelas donde asisten niños latinos, los responsables de estas instituciones suelen tomar la decisión de trabajar de forma bilingüe, ampliar las tutorías, etcétera.

Desde la experiencia de los estudiantes migrantes, advertimos las diferencias que ellos identifican, centradas en la manera en que se distribuye el tiempo, el tipo de actividades, las formas de enseñanza y los recursos educativos.

Allá más nos enseñaban todo el día y acá no, a veces no hacemos nada aquí, me aburro $\left(\mathrm{E}^{\circ}{ }^{\circ}\right)$ - Allá nos enseñaban de otra forma y aquí de otra, allá se me hacía más fácil, aquí no, aunque estoy menos tiempo, aquí nos pasamos haciendo lo mismo $\left(\mathrm{E}^{\circ}\right)$. -Me gustaba más allá, porque hacíamos más cosas, nos enseñaban que debíamos hacer para no enfermarnos, ciencia, leíamos, salíamos a museos, al zoo, nos sacaban, había más materiales; aquí siempre es lo mismo $\left(\mathrm{E} 6^{\circ}\right)$. -Allá enseñan mucho inglés, acá no puedo bien el español $\left(\mathrm{E} 2^{\circ}\right)$. -Acá salimos a la una, eso me gusta, allá salíamos más tarde $\left(\mathrm{E} 2^{\circ} \mathrm{A}\right)$.

Los estudiantes reconocen que son diferentes las prácticas áulicas de Estados Unidos y México y aunque advierten a la escuela mexicana como rutinaria y aburrida, ellos tienen un papel activo y propositivo: "A mí me gustaría enseñarles inglés a mis compañeros" $\left(\mathrm{E} 1^{\circ} \mathrm{B}\right)$; y realizan actividades vinculadas con la forma en que saben trabajar, cuando el propio currículo demanda actividades autónomas, por ejemplo en el trabajo por proyectos.

Las madres identifican las formas de trabajo de las escuelas de México y Estados Unidos en dos aspectos sustantivos, uno, el vínculo enseñanza aprendizaje y dos, la responsabilidad de los profesores. Del primer aspecto, advierten que, en Estados Unidos, al no ser numerosos los grupos, trabajan de manera más personalizada con los estudiantes: "allá les dan su tiempo para aprender, les dan más actividades, no los dejan así nada más sin que aprendan. Si alguien no entiende, se acerca la maestra o la asistente y lo apoyan" (M2). También señalan que los niños tie- 
nen tutorías dentro de la escuela o fuera, si es necesario. En este caso, refieren que algunos se quedan más tiempo en la escuela o van a clases especiales para que se nivelen.

Lo anterior nos permite advertir que las madres, de manera directa o indirecta, conocen la forma de trabajo de las escuelas estadounidenses y valoran el trabajo personalizado que se realiza en estas. Por esa razón, la mediación de la madre con la escuela mexicana y sus hijos es demandar a los profesores una atención especial a los primeros, además de participar activamente en la escuela incluso en proyectos novedosos para ellas: "Llegando acá, vemos que les enseñan más cosas del país, su cultura, el náhuatl, eso me parece bien, por eso apoyo. La cultura es muy importante" (M1).

Sobre el aspecto de responsabilidad refiere una madre:

Aquí, si no llega el maestro, se perdió todo el día; eso no me gusta porque allá [en las escuelas de Estados Unidos] siempre hay un sustituto que trabaja con los niños lo que la maestra organizó para ese día $\left(\mathrm{M}^{\circ}\right)$.

Las madres identifican que es responsabilidad de la escuela que sus hijos aprendan, para ello reconocen aspectos como el uso efectivo del tiempo y el cumplimiento de la planeación. Debido a ello, las madres son críticas con la escuela mexicana cuando identifican el incumplimiento de los profesores. Pero también es de señalar que no logran interesarse por el enfoque pedagógico de las asignaturas, al parecer no llegan a reconocerlo, a pesar de que los nińos señalan que se aburren, que escriben mucho, cuestión que permite mostrar que los profesores no trabajan del todo con la reforma educativa de 2011, que plantea el uso funcional de la lengua, la resolución de problemas y actividades por proyectos (SEP, 2011), aspectos que el Modelo Educativo que se pondrá en marcha en el ciclo escolar 2018-2019, también recupera (SEP, 2017).

\section{Demandas y determinaciones de las madres migrantes}

En un contexto institucional fuertemente normado por leyes constitucionales y regulado en su operación por la Secretaría de Educación Pública, encontramos señalamientos respecto a la par- 
ticipación de padres de familia en la escolarización de sus hijos, instando a su intervención en las escuelas, cuando señala que "deberá asegurarse la participación activa de todos los involucrados en el proceso educativo, con sentido de responsabilidad social, privilegiando la participación de los educandos, padres de familia ${ }^{20}$ y docentes"(Cámara de Diputados, 2013, s/f), esto con el interés de lograr los fines de la educación estipulados en el artículo $3^{\circ}$ constitucional.

En el Modelo Educativo que se pondrá en marcha en 2018, se reconoce que "el involucramiento de las madres y los padres de familia es un factor que incide altamente en el desempeño académico y el desarrollo de los estudiantes" (SEP, 2017: 178), y se les asigna un papel activo en la gestión escolar, la transparencia y la rendición de cuentas. En el plano de la organización y operatividad escolar, los reconoce como apoyos "para que se cumpla en la escuela la normalidad mínima ${ }^{21}$ y para contribuir en actividades extracurriculares" (ibid.: 180). Advertimos que este reconocimiento conlleva al mismo tiempo una limitación, al identificarlos simplemente como "apoyos" del directivo y profesores, así como de otorgarles un papel de vigilancia respecto a la transparencia y rendición de cuentas de la institución. Únicamente de manera marginal, en el plano educativo, les confiere participar en actividades extracurriculares, acciones todas a la sombra de las decisiones torales de la vida escolar.

En este marco institucional fuertemente regulado, donde la participación se centraliza en las autoridades educativas, adverti-

\footnotetext{
${ }^{20}$ En los documentos tanto reglamentarios como operativos de orden oficial en el Sistema Educativo Nacional, en el nominativo "padres de familia" también quedaba implícita la referencia a las madres; es en el documento "Modelo Educativo para la educación obligatoria" (SEP, 2017), donde encontramos un cambio al hacer referencia también a las "madres de familia”.

${ }^{21}$ La SEP planteó en Las guías de los Consejos Técnicos y en el Acuerdo 711 (SEP, 2013) la normalidad mínima que las escuelas de educación básica deben cumplir para su buen funcionamiento. Esta se cumple en ocho rasgos: a) todas las escuelas brindan el servicio educativo los días establecidos en el calendario escolar; b) todos los grupos disponen de maestros la totalidad de los días del ciclo escolar; c) todos los maestros inician puntualmente sus actividades; d) todos los alumnos asisten puntualmente a todas las clases; e) todos los materiales para el estudio están a disposición de cada uno de los estudiantes y se usan sistemáticamente; f) todo el tiempo escolar se ocupa fundamentalmente en actividades de aprendizaje; g) las actividades que propone el docente logran que todos los alumnos participen en el trabajo de la clase; $\mathrm{y}$ h) todos los alumnos consolidan su dominio de la lectura, la escritura y las matemáticas, de acuerdo con su grado escolar.
} 
mos la participación de las madres migrantes, quienes de manera cotidiana interactúan, más allá de la regulación oficial, con los agentes escolares (director y profesores) de la escuela, tanto en acciones que se relacionan con las estipuladas por la SEP, como planteando nuevas demandas y posicionándose en la escuela desde el sentido que para ellas tiene la institución, más allá de las lógicas de poder en que esta se estructura (Zemelman, 1998) e intentando construir, desde sus experiencias y expectativas, otras formas de ser y estar en la escuela.

Más allá de la estructura normada de las escuelas, reconocemos que las madres migrantes aparecen como agentes mediadoras entre sus hijos y la institución escolar, que no es ajena a ellas debido a que se escolarizaron en nuestro país, ${ }^{22}$ pero también se acercaron a otras escuelas en Estados Unidos, lo que les posibilitó conocer e interactuar desde el proceso de enseñanza aprendizaje de sus hijos. ${ }^{23}$

En principio, ellas se muestran interesadas en la educación de sus hijos, llegan con una actitud mental que es producto de las expectativas que aún tienen sobre la escolarización, de la necesidad de sus hijos de adquirir aprendizajes para la vida en la realidad trasnacional que viven, así como de la experiencia acumulada como madres de familia en las escuelas de Estados Unidos y ahora de México, por lo que intentan, reconociendo las limitaciones de la escuela, mediar, demandando en lo posible que se transforme a semejanza de la escuela estadounidense, en relación con las formas de trabajo, insumos y desarrollo del bilingüismo de sus hijos.

Colaboran con la escuela y, a cambio, piden cosas extras. Exigen que se cumpla el currículum, que los maestros no falten, que se apoye a sus hijos en temas que se les dificultan. El argumento

\footnotetext{
${ }^{22}$ La mayoría de las madres de este estudio (19) realizaron en México la educación primaria y algunos años de la educación secundaria. Únicamente M1, antes de migrar a Estados Unidos, estudió hasta cuarto año de primaria, pues migró de niña y siguió su escolarización en aquel país concluyendo el Community College.

${ }^{23}$ Encontramos que estas madres asistían muy poco a la escuela de sus hijos en Estados Unidos, porque se sentían ajenas a la institución, no sabían hablar inglés y porque tenían horarios laborales que les impedían acercarse a la escuela. Esto cambia radicalmente en México porque, al llegar a Nealtican, cuentan con más tiempo que quieren dedicar a sus hijos, sienten familiaridad con la escuela mexicana y la comparan con la de Estados Unidos advierten sus carencias y deficiencias.
} 
principal de las madres es la experiencia que tuvieron sus hijos en la escuela estadounidense.

Allá había atención para cada niño, si no entendía, la maestra se acercaba, le explicaba, le dejaba tareas extras, mandaba llamar a los padres, te hablaban por teléfono $y$, si no podías asistir, te esperaban por la tarde, te explicaban cómo ayudar a tú hijo y si era necesario que el niño tuviera clases personales, entraba más temprano o salía más tarde hasta que aprendía. También les dicen a los padres que tienen que ir a gabinete con un psicólogo sin pagar $\left(\mathrm{M}^{\circ}{ }^{\circ}\right)$.

En la escuela de Estados Unidos también había maestros que hablaban español y trabajaban unas materias con los niños. Otras eran en inglés, los niños se integraban a la clase general con el maestro del grupo, creo que así aprendieron inglés sin dejar el español, pero aquí no hay escuelas bilingües, aquí es puro español, enseñan bien, pero dejan a un lado el inglés $\left(\mathrm{M}^{\circ}{ }^{\circ}\right.$ ).

La mediación de las madres entre el aprendizaje de sus hijos y las formas de enseñanza de la escuela es una forma de confrontar a la institución mexicana y a la propia SEP, ya que el discurso de las madres hacia el director y los profesores pone en tensión las formas tradicionales basadas en la enseńanza y no en el aprendizaje.

Cuestionar y mediar, generando controversia, acerca de los recursos humanos, financieros y materiales de escuelas marginadas en zonas rurales, también es una forma de confrontación pacífica ante la precariedad de los planteles y las demandas de las madres por una educación pertinente para sus hijos, que requieren de una formación trasnacional.

No obstante, la escuela solo permite que "los padres y madres puedan opinar, pero rara vez incidir en las decisiones; pueden acceder al ámbito escolar y local, pero no al de las políticas educativas"(Torres, 2006: 26). Resulta importante la mediación de las madres como confrontación cuando de ello depende incidir hacia el cambio y con ello a la participación y a la democracia escolar que implica la responsabilidad de todos. 


\section{Consideraciones finales}

La presencia de estudiantes trasnacionales en la escuela mexicana no es reciente, sin embargo, no existen políticas educativas pertinentes que cubran las necesidades educativas de estos niños y jóvenes. Ante ello, la presencia de las madres como actores sociales que median entre estos estudiantes y la institución escolar posibilita que los niños se integren a ella, esto desde un posicionamiento activo.

Tras advertir que "los sistemas educacionales públicos han sido siempre espacios de tensión entre Estado y sociedad y al mismo tiempo espacios de vinculación" (Puiggrós, 2010: 59), reconocemos en esta relación compleja, que las madres de los niños inmigrantes son agentes mediadores que impugnan a la institución educativa con demandas específicas que la propia escuela no contemplaba en sus prácticas educativas y sin embargo, intenta (con evidentes dificultades), responder a ellas.

Más allá de la importante presencia de las madres migrantes en la escuela, es necesario apuntar que "la participación de los padres es necesaria, pero no suficiente para mejorar los resultados de los alumnos. Es fundamental un compromiso serio de la nación" (Apple, 2001: 140). Por ello, la mediación de las madres constituye un factor propicio para que el Estado construya un proyecto que potencie los aprendizajes y formas de aprender de estos estudiantes.

Reconocemos la importancia del papel mediador de las madres en la escolarización de sus hijos. Esta mediación la advertimos en dos sentidos, uno, como vínculo entre la institución escolar y los hijos, mediante una participación activa y propositiva, tomando en cuenta el interés que muestran por apoyarlos y su participación en las actividades a las que son convocadas, lo que obliga a los docentes a poner atención a estos estudiantes y brindarles un trato cordial, sin que por ello los profesores estén dejando de mantener su autoridad y, en ocasiones, autoritarismo.

Y dos, desde la controversia, al demandar más a la escuela, exigen fundamentalmente dos cosas: responsabilidad de los profesores y un proceso de enseñanza aprendizaje que tome en cuenta los diferentes procesos de aprendizaje de los estudiantes y sus necesidades educativas como lo es el bilingüismo. 
La escuela mexicana recibe e interactúa con el estudiante inmigrante desde la diferencia, lo considera extraño al grupo. Es allí, donde las madres son mediadoras y facilitadoras en el proceso de inserción de sus hijos. Nos parece que el papel de las madres migrantes en relación con la escolarización de sus hijos cobra importancia para trasformar la escuela mexicana (al igual que la participación activa de otros agentes educativos). De esta manera, la mediación de las madres como una intervención inesperada (interventus us) para una escuela rutinaria y tradicional, trastoca lo constituido para dar paso a algo más, la verdadera participación de los agentes sociales en la escuela, ya que "la participación en educación es condición indispensable en el hecho educativo y de la propia eficacia de la política educativa" (Torres, 2006: 26) donde aparecen los intereses de los agentes educativos, quienes plantean lo mismo que las madres migrantes, nuevas necesidades, acordes con la realidad que viven, en este caso, la trasnacionalidad.

\section{Referencias bibliográficas}

Apple, Michel. Politica culturaly educación, Madrid, Morata, 2001. Ariza, Marina y Orlandina de Oliveira. "Familias en transición y marcos conceptuales en redefinición", en Papeles de Población, núm. 28, abril-junio, Toluca, Universidad Autónoma del Estado de México, 2001, pp. 9-39.

Backhoff, Eduardo et al. Aprendizaje y desigualdad social en México, México, INEE, 2007.

Blanquez, Agustín. Diccionario manual latino-español y españollatino, Barcelona, Sopena, 1978.

Bourdieu, Pierre y Jean Passeron. Los herederos. Los estudiantes y la cultura, México, Siglo XXI, 2003.

Cámara de Diputados. "Ley Federal de Educación”, en Diario Oficial de la Federación, México, 2013.

Cámara de Diputados. Acuerdo 711 por el que se emiten las Reglas de Operación del Programa para la Inclusión y la Equidad Educativa, México, 2013.

Cazarny-Krischkautzky, Gabriela. "Pasar por la escuela. Metáfora que guarda distintas caras para abordar la relación comunidades indígenas y escolaridad, en Revista Mexicana de Investigación Educativa, vol. XII, núm. 34, 2007, pp 921-950. 
CONEVAL. Porcentaje de población en situación de pobreza en Puebla 2010, México, CONEVAL, s/f.

Cortina, Regina. "Factores transnacionales y el desempeño escolar de los inmigrantes mexicanos", en Regina Cortina y Mónica Gedreau, Poblanos en Nueva York. Migración rural, educación y bienestar, Puebla, Universidad Iberoamericana, Puebla, 2004, pp. 57-76.

Cortina, Regina. "La educación de los latinos en las escuelas del norte de Manhattan, en Caja negra. Revista de ciencias políticas y humanidades, núms. 8/9, Puebla, BUAP, 20102011, pp. 113-130.

Durand, Jorge y Douglas Massey. Clandestinos. Migración México-Estados Unidos en los albores del siglo XXI, México, Miguel Ángel Porrúa, 2009.

Ferry, Gilles. El trayecto de la formación (los enseñantes entre la teoría y la práctica), México, Paidós, 1994.

Franco, Martha. "Escuelas de Papel: Intervención Educativa en una institución donde asisten niñas y niños migrantes", en Sinéctica, núm. 43, julio-diciembre, 2014,pp.01-20. Disponibleen http:// www.scielo.org. $\mathrm{mx} / \mathrm{scielo}$.php?script $=$ sci_ arttext\&pid=S1665109X2014000200009\&lng=es\&nrm=iso\&tlng=es.

Foucautl, Michel. Vigilar y castigar. Nacimiento de la prisión, México, Siglo XXI, 2005.

Hernández, Gerardo. Paradigmas en psicología de la educación, México, Paidós, 1998.

INEGI. Censo de Población y Vivienda 2010. Nealtican, Puebla, Disponible en http://www.inegi.org.mx/sistemas/mexicocifras/default.aspx? src $=487 \& \mathrm{e}=21,2011$.

Jacobo, Mónica. "Desafíos actuales de la escuela monolítica mexicana: el caso de los alumnos migrantes trasnacionales, en Sinéctica, núm. 47, julio-diciembre, 2016, pp. 1-12. Disponible en https://sinectica.iteso.mx/indexphp/SINECTICA.

La Jornada. "La crisis de los niños migrantes" en La jornada en linea. Disponible en http://www.jornada.unam.mx/ultimas/2014/07/02/la-crisis-de-los-ninos-migrantes, 2014.

Larrosa, Jorge. "La experiencia y sus lenguajes", en Estudios $f_{i-}$ losóficos, vol. 55, núm. 160, España, 2006, pp. 467-480.

Levitt Peggy y Nina Glick. "Perspectivas internacionales sobre migración”, en Portes Alejandro y Josh De Wind, Repensando 
las migraciones. Nuevas perspectivas teóricas y empiricas, México, INM/UAZ/Miguel Ángel Porrúa, 2006, p.p. 191- 229.

López, Gustavo. "La educación en la experiencia migratoria de niños binacionales", en Fronteras fragmentadas. Género, familia e identidades en la migración mexicana al norte, XIX Coloquio de antropología e historia regionales, Zamora, El Colegio de Michoacán, 1997.

Martínez, Ana. "Procesos de mediación", en Seminario Permanente Alternativas Pedagógicas y Prospectivas en América Latina, México, FFL-UNAM, 2014.

Martínez José. "El derecho a la educación en los Estados Unidos de América", en Revista Española de Derecho Constitucional, núm 93, septiembre-diciembre, Madrid, 2011, pp. 65-106.

Mc Carthy, C. Racismo y currículum, Madrid, Morata, 1994.

Mc Laren, Peter. La vida en las escuelas. Una introducción a la pedagogía crítica en los fundamentos de la educación, México, Siglo XXI, 1994.

Mier, Raymundo. "Migración e infancia, de los cuerpos confinados, a la invención de la experiencia", en Foro invisibilidad y conciencia: Migración Interna y niños jornaleros agrícolas en México, México, 2002.

Pew Hispanic Center. Hispanos de origen mexicano en los Estados Unidos, 2008, Washington D. C., Pew Research Center, 2010.

Puiggrós, A. La tremenda sugestión de pensar que no es posible, Buenos Aires, Galerna, 2010.

Torres, Rosa. "Derecho a la educación es mucho más que acceso de niños y niñas a la escuela", en X Congreso Nacional de Educación Comparada. El derecho a la educación en un mundo globalizado, San Sebastián, X CNEC, 2006, pp. 1-31.

Schutz, Alfred. "El forastero. Ensayo de psicología social" en Georg Simmel et al., El extranjero, Madrid, Sequitur, 2012, pp. 27 a 42.

Schutz, Alfred y Thomas Luckman . Las estructuras del mundo de la vida, Buenos Aires, Amorrortu, 2009.

SEP. Modelo Educativo para la Educación Obligatoria, México, SEP, 2017 SEP. Plan de Estudios 2011. Educación Básica, México, SEP, 2011. Smith, Robert. "CUNY y el futuro educativo de los mexicanos en Nueva York", en Caja negra. Revista de ciencias politicas y humanidades, núms 8/9, Puebla, BUAP, 210-2011, pp. 131-147.

Smith, Robert. "Imaginando los futuros educativos de los mexicanos en Nueva York", en Regina Cortina y Mónica Gen- 
dreau (cords.), Poblanos en Nueva York. Migración rural, educación y bienestar, Puebla, Universidad Iberoamericana Puebla, 2004, pp. 87-112.

Suárez, Carola y Desirée Baolian. "Inmigrant Boys' Experiences in US School", en Niobe Way y Judy Chu, Adolescent Boys. Exploring Diverse Cultures of Boyhooh, Nueva York: University Prees, 2004, pp. 295-316.

Tinley, Alicia. "Migración de Guanajuato a Alabama. Experienias escolares de cuatro familias mexicanas", Sociológica, vol. 21, núm. 60, enero-abril, 2006, pp 143-172.

Trigueros, Paz. "La migración femenina mexicana hacia Estados Unidos y su participación en el mercado laboral de ese país", en Delgado Raúl y Margarita Favela (coords.), Nuevas tendencias y desafios de la migración internacional México-Estados Unidos, México, Miguel Ángel Porrúa/ Gobierno de Zacatecas/ UNAM, 2004, pp. 97-126.

Tyack, David and Tobin William. "The Grammer of Schooling: Why Has it Been so Hard to Change?, en American Educational Research Journal, Fall, vol. 31, núm. 3, 1993, pp. 453-479.

UNICEF. Convención sobre los derechos del niño, Nueva York, ONU, 1989. UNICEF. La travesía. Migración e infancia, México, UNICEF, 2011. UNICEF. Niñas y niños inmigrantes en México, México, UNICEF, s/f. Valdéz, Gloria. "Introducción” en Valdéz, Gloria (coord.), Movilización, migración y retorno de la niñez migrante. Una Mirada Antropológica, Hermosillo, Colegio de Sonora, 2012, pp. 13-38.

Vygotsky, Lev. Pensamiento y Lenguaje, México, Quinto Sol, 2013. Yu, Huang, Schwalberg, Overpeck, y Kogan. "Acculturation and the health and well being of US immigrant adolescents", en The Journal of Adolescent Health, vol. 33, núm. 6, 2003, pp. 479-488.

Yurén, Teresa. Formación y puesta a distancia. Su dimensión ética, México, Paidós, 2000.

Zemelman, Hugo. El conocimiento como desafío posible, México, IPN, 1998.

Zúniga, Víctor (2013). "Migrantes internacionales en la escuela mexicana: desafíos actuales y futuros de política educativa”, en Sinéctica, núm. 40, enero-junio, 2013, pp. 1-12. Disponible en http://www.redalyc.org/articulo. oa?id=99827467009, 2013. 